\title{
Uma troca materno-fetal no equilibrio de oxigênio das hemoglobinas dos caecílios vivíparos, Typholonectes compressicauda [*]
}

\author{
Robert L. Garlick ('); Bonnie J. Davis $\left({ }^{2}\right)$; Martha Farmer $\left({ }^{3}\right)$; Hans Jorgen Fyhn $\left({ }^{3}\right)$; Unni E. H. Fyhn ( $)$; \\ Robert W. Noble $\left({ }^{5}\right)$; Dennis A. Powers ( $\left.{ }^{6}\right)$; Austen Riggs ('); Roy E. Weber ( $)$
}

\begin{abstract}
Resumo
Mediram-se o equilíbrio e a cinética de ligação do oxigênio pelo sangue e hemoglobina de adultos $\theta$ fetos de Typholonectes compressicauda. A afinidade pelo oxigênio do sangue fetal é mais alta do que a do sangue do adulto. A eletroforese das hemoglobinas fetal e adulta sugere que elas podem ser idênticas, ocorrendo um componente principal e um secundário em cada uma delas. As hemoglobinas adulta e fetal possuem Idêntico equilíbrio de oxigênio. Hemoglobinas fracionadas possuem uma alta afinidade pelo oxigênio e nenhum efeito Bohr entre $\mathrm{pH} 6,5$ e 10,0. Um efeito Bohr reverso "ácido" está presente abaixo de $\mathrm{pH}$ 6,5. A adição de $1 \mathrm{mM}$ de ATP reduz acentuadamente a afinidade de oxigênio e produz um efeito Bohr normal moderado. O principal nucleosídeo trifosfato nos eritrócitos fetais e adultos é adenosina trifosfato; cerca de $10 \%$ dos nucleosídeos trifosfatos são guanosina trifosfato. Eritrócitos dos adultos contém 3 vezes mais ATP do que os eritrócitos fetals. A troca fetal-maternal, no equilibrio de oxigênio, é mediada inteiramente pela diferença no conteúdo de ATP das células sangüineas verme Ihas maternas e fetais.
\end{abstract}

\section{INTRODUÇÃo}

Os caecilios tropicais ápodos pertencem à ordem Gymnophiona, os quais, juntos com os urodelos e anuros, compreendem as três ordens de anfíbios viventes (Taylor, 1968). O registro fóssil de caecílios consiste apenas de uma única vértebra; provou-se que os dois supostos fósseis mais primitivos pertenciam, um, a um bagre e outro a um molusco (Estes \& Wake, 1972). Algumas espécies de caecílios escavam o solo úmido; outras são aquáticas. Algumas são ovíparas, mas, há mais, de cem anos, Peters (1875) descobriu espécimes fetais nos ovidutos do caecílios aquático, Typholonectes compressicauda e Parker (1956) mostrou que o desenvolvimento não é ovovivíparo mas vivíparo, por meio do qual o feto recebe nutrição da mãe. Estas espécies vivem em buracos submersos, em bancos de lama dos rios da bacia amazônica. O comportamento de reprodução foi descrito recentemente (Murphy et al., 1977). Cada feto possui um par de brânquias externas grandes, altamente vascularizadas, as quais são perdidas logo após ao nascimento.

Towes \& Macintyre (1977) observaram que a afinidade pelo oxigênio do sangue total de fetos de $T$. compressicauda é mais alta do que a do adulto. Esta diferença fetal-maternal pode facilitar as trocas gasosas, através da parede do oviduto para as brânquias fetais.

Neste trabalho, descreve-se a base fisiológica e bioquímica para a troca fetal-maternal na afinidade de oxigênio entre os sangues do adulto e o feto de Typholonectes compressicauda.

\section{MATERIAIS E MÉTODOS}

Espécimes do caecílios aquático, Typholonectes compressicauda, foram obtidos de um pescador local em novembro, 1976, durante a IV Expedição amazônica R/V "Alpha Helix", em uma área no rio Solimões (Amazonas), cerca de 30 milhas acima da sua junçẩo com o rio Negro, perto de Manaus, Brasil. O período de coleta foi no final da estação seca, quan. do o nível da água é o mais baixo. Dezesseis

\footnotetext{
(*) - Versão original inglesa publicada em Comp. Blochem. Physiol. vol. 62 A (1). 1979.

(1) - Department of Zoology, University of Texas, Austin, Texas 78712, U.S.A.

(2) - Departnemt of Biology, San Francisco State Univer sity, San Francisco, California 94132, U.S.A.

(3) - Duke University Marine Laboratory, Beaufort, Norih Carolina 28516, U.S.A.

(4) - Institute of Zophysiology, University of Oslo, Blindern, Oslo 3, Norway.

(5) - Department of Medicine and Biochemistry, Veterans Administration Hospital, State University of New York, Buffalo, New York., U.S.A. Esblished Investigator of the American Heart Association.

(6) - Department of Biology, Johns Hopkins University, Baltimore, Maryland 21218, U.S.A.

(7) - Institute of Zoophysiology, University of Aarhus, Aarhus, Denmark.
} 
animais adultos jovens, medindo de 37 a 72 $\mathrm{cm}$ de comprimento e de 43 a $250 \mathrm{~g}$ de peso, foram estudados. Cinco dos animais (170 a $250 \mathrm{~g}$ cada) possuiam fetos em estado avançado de desenvolvimento nos ovidutos. O número de fetos era de 6 a 13 por animal, e pesavam de 5 a $10 \mathrm{~g}$ cada. Os fetos possuiam duas grandes $(7 \times 13 \mathrm{~cm})$ brânquias externas em forma de folha fixas dorso-lateralmente. Foi feita sangria em 25 fetos imediatamente após terem sido retirados de três fêmeas adultas. Uma fêmea pariu três jovens, os quais foram sangrados, após terem sido mantidos por 8 horas em um aquário. Um jovem foi mantido por 14 dias em um aquário antes de ser-lhe feita a sangria.

Os adultos foram sangrados por perfuração cardíaca após terem sido congelados. Entre 5 e $15 \mathrm{ml}$ de sangue, de cada animal, foram recolhidos em uma seringa de vidro, heparinizada, fria. (100 $\mu$ l sódio-heparina, 5000 unidades internacionais/ $\mathrm{ml} \mathrm{em} 1,7 \% \mathrm{NaCl}$ por $5 \mathrm{ml}$ sangue). Os fetos foram sangrados cortandose-lhes as caudas. Cerca de 100-400 $\mu$ l de sangue foram coletados de cada feto em tubos de ensaio heparinizado a $5^{\circ} \mathrm{C}$. Medidas hematocríticas, preparação hemolisada, disco de gel-alcalino para eletroforese $(\mathrm{pH} 8,9)$, registro do gel, sulfato de sódio dodecil (SDS em gel de poliacrilamida para eletroforese, foram feitos como o descrito em Fyhn et al. (1978). A razão entre a distância de migração eletroforética de um componente de uma hemoglobina e o serum de albumina bovina calculada para cada gel foi usada para comparar a mobilidade relativa de componentes de hemoglobina em geis de diferentes corridas.

Equilibrio de oxigênio do sangue total de fetos e adultos de $T$. compressicaudas foi determinado com um analisador de dissociação de oxigênio Hem-O-Scan (American Instrument Co., Silver Spring, Md.) como o descrito por Powers et al. (1978). Todo o sangue heparizado foi desoxigenado com $99,999 \%$ de nitrogênio, ou $94,4 \%$ de nitrogênio mais $5,6 \%$ de $\mathrm{CO}_{2}$; e foi reoxigenado com $100 \%$ de ar com $21 \%$ de oxigênio ou $69,4 \% \mathrm{~N}_{2}, 25 \% \mathrm{O}_{2}$ e $5,6 \%$ $\mathrm{CO}_{2}$, as amరిstras de sangue não foram tamponadas, o valor de $\mathrm{pH}$ do sangue de cada animal foi tomado como a média do sangue desoxige- nado e totalmente oxigenado e variaram consideravelmente de animal para animal.

Hemoglobina para os experimentos de equilíbrio de oxigênio e cinética rápida, foi cromatografada primeiro em uma coluna de $2 \times 50$ $\mathrm{cm}$ de Sphadex G-25 meio, em 0,1 mM Tris pH 8,5 e passada, então, em uma coluna deionizante $(1,5 \times 30 \mathrm{~cm})$ consistindo das seguintes resinas de cima para baixo: $2 \mathrm{~cm}$ Dowex-1 (em forma de acetato), $2 \mathrm{~cm}$ Dowex-50W (íon em forma de amonio) e $20 \mathrm{~cm}$ de Bio Rad AG 501X8(D) resina de troca iônica de camada mista. Esta hemoglobina fracionada foi ajustada para cerca de $30 \mu \mathrm{M}$ (heme) em tampão de força iônica constante $(I=0,05)$ e $\mathrm{Cl}$ constante feito com Tris ou Bis Tris. Medidas do equilibrio do oxigênio foram feitas a $20^{\circ} \mathrm{C}$ em vidros tonométricos (Riggs \& Wolbach, 1956). O vaolr para $P_{50}$, o oxigênio para meia saturação em $\mathrm{mm} \mathrm{Hg}$ e o coeficiente " $n$ " de Hill foram determinados da média da inclinação da representação gráfica de Hill para os dados colocados entre 25 e $75 \%$ de oxigenação. Os equilibrios de oxigênio foram determinados para hemoglobina fracionada com e sem $1 \mathrm{mM}$ de ATP.

Todas as medidas cinéticas foram com um aparelho regulador de fluxo do tipo originalmente descrito por Gibson \& Milnes (1964). A força iônica da soluçăo final foi de $0,05 \mathrm{em}$ todo o experimento. Quando o ATP foi usado, estava em uma concentração de $1 \mathrm{mM}$ após a mistura. Os cálculos da constante cinética são derivados do ajuste dos pontos pelo método dos mínimos quadrados feito com os dados dos $65 \%$ das reaçõєs observadas inicialmente.

As dissociações cinéticas do oxigênio foram medidas em diferentes $\mathrm{pH}$ procedimento descrito por Noble et al. (1970). A hemoglo bina oxigenada em $1 \mathrm{mM}$ Tris, no $\mathrm{pH} 8,0$, foi misturada a uma solução de ditionito de sódio em tampão de força iônica de 0,1 no pH desejado. A concentraçäo final da hemoglobina foi cerca de $30 \mu \mathrm{M}$ (heme) e a reação foi seguida a 560 e $540 \mathrm{~nm}$.

As cinéticas de combinação do monóxido de carbono com hemoglobina desoxigenada foram medidas por misturas de soluçōes de hemoglobina desoxigenada em tampão de força iônica 0,1 de $\mathrm{pH}$ desejado com uma solução 
contendo $85 \mu \mathrm{M}$ de $\mathrm{CO}$ em água. Depois da mlstura, a concentração de hemoglobina foi de cerca de $3 \mu \mathrm{M}$ (heme). A reaçäo foi seguida a 420 e $435 \mathrm{~nm}$.

A concentração total do nucleotídeo trifosfato nos eritrócitos foi medida enzimaticamente com um equipamento NTP (produto número 366-UV, Sigma Chemical Co., St. Louis, Mo.). Na análise, usamos fosfoglicerato fosfoquinase e gliceraldido fosfato deidrogenase e munitorariamos o decréscimo na absorbância a $340 \mathrm{~nm}$ acompanhando a oxidação $\mathrm{NADH}$ a $\mathrm{NAD}+$ :

O total de ATP nos eritrócitos foi medido da seguinte maneira: $150 \mu \mathrm{l}$ de sangue foram coletados em um tubo capilar heparinizado. O sangue foi imediatamente suspenso em $6,0 \mathrm{ml}$ $0,9 \% \mathrm{NaCl}$ em $10 \mathrm{mM}$ fosfato, $\mathrm{pH} 7,0$ a $4^{\circ} \mathrm{C} ; 3,0 \mathrm{ml}$ foram removidos para determinação de hemoglobina e $2,0 \mathrm{ml}$ foram removidos para determinação de ATP. Ambas as alíquotas foram transferidas para tubos de polipropileno de $10 \mathrm{ml}$ e centrifugadas para aglutinar os eritrócitos. Depois de removido o sobrenadante, os eritrócitos usados para determinação de hemoglobina foram lisados com $2,0 \mathrm{ml}$ de fosfato $10 \mathrm{mM}$ a frio, $\mathrm{pH} 7,0$. O estroma foi removido por centrifugação e a absorbância da solução transparente foi medida a $540 \mathrm{~nm}$ como $\mathrm{HbCO}$. Os agregados de eritrỏcitos usados para análise de ATP foi lisado com $5,0 \mathrm{ml}$ de $0,05 \mathrm{~N} \mathrm{de} \mathrm{HNO}_{3}$ a frio. proteína precipitada e o estroma foram removidos por centrifugação a $4^{\circ} \mathrm{C}$. O sobrenadante foi diluído 100 vezes com água destilada deionizada. As amostras diluídas foram examinadas dentro de 4 minutos para minimizar a hidrólise do ATP. Uma luciferase de vaga-lume modificada para analisis de ATP (Greaney e Powers, 1977) foi usada com um fotômetro acoplado a um gravador de duplo canal Sanborn. Uma alíquota $(0,1 \mathrm{ml})$ da amostra foi injetada dentro da solução cuveta contendo $0,1 \mathrm{ml}$ de uma solução de luciferase (Instituto Dupont, Wilmington, Del.) . A altura do pico descrito no gravador é proporcional à intensidade de luz a qual por seu turno é proporcional à concentração de ATP na amostra. O sistema de análise foi calibrado diariamente com padrões preparados momentos antes do experimento. A intensidade de luz foi linear com uma concentração entre $1 \mathrm{ng}$ e $1 \mu \mathrm{g}$ de ATP por $\mathrm{ml}$. As amostras, usualmente, continham ATP próximo de $5 \times 10^{-8} \mathrm{~g} / \mathrm{ml}$. Todas as amostras correram em triplicata.

As concentrações de ATP a GTP no sangue (desproteinizado com um volume de 10\% de ácido tricloroacético) foram também determinadas com uma cromatografia de camada fina como descrita por Cashel et. al. (1968) e modificada por Weber et al. (1976) com placas portadoras de celulose (CEL 300, PEl-Macherey, Nagel Co., Duren, Alemanha Ocidental).

\section{Resultados}

Os padrões eletroforéticos para as hemaglobınas do sangue do adulto e do feto de T. compressicauda foram idênticos (Fig. 1). 0 hemolisado teve um componente principal com uma mobilidade de 0,53-0,54 em relação ao serum de albumina bovina. A hemoglobina-A humana teve uma mobilidade relativa $0,66 \pm 0,01$ (média \pm desvio padrão, $\mathrm{N}=5$ ). Na maioria dos geis um componente mais lento com uma mobilidade relativa de $0,44 \pm 0,02(N=41)$, estava presente em quantidades variando de $5-25 \%$ da quantidade total de hemoglobina. Um componente secundário abrangendo menos de $5-10 \%$ da hemoglobina e com uma mobilidade relativa de $0,32 \pm 0,02(N=15)$ foi observado nos geis depois da armazenagem do hemolisado.

Os pesos moleculares das cadeias de hemoglobinas nos adultos, jovens e fetos, em eletroforese gel e SDS foram todos encontrados estando por volta de 17.200 . Isto é ligeiramente mais alto que o peso molecular encontrado para as cadeias de hemoglobina humana desnaturada, 14.600 e do peso molecular encontrado para as hemoglobinas desnaturada dos peixes amazônicos, 14.200-17.200 (Fyhn et al., 1978).

O hematócrito de sangue de uma espécie grávida de $T$. compressicauda foi de $26 \pm 10 \%$ (média \pm desvio padrão, $N=5$ ), a qual foi muito menor quando em comparação com $\alpha$ sangue das espécies não grávidas $(48 \pm 9 \%, N=9)$. Nenhuma correlação foi encontrada entre hematócrito e peso do corpo. O método de sangramento impediu determinações de hematócrito do sangue dos fetos. 


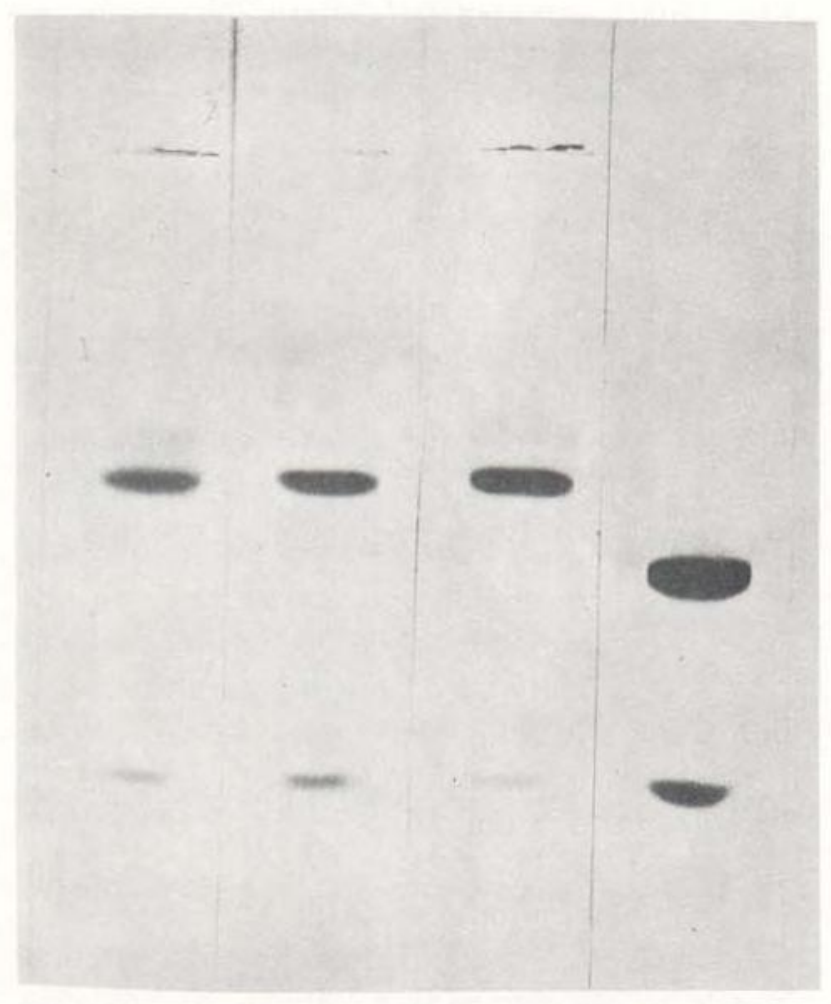

Fig. 1 - Eletroforese em disco gel de pollacrilamida dos hemolisados de adultos e fetos de T. compresscauda e de homem. Da esquerda para a direita: hemolisado de adulto de T. compressicauda; hemolisado de feto de T. compressicauda; hemolisado de feto mais adulto de T. compressicauda; hemolisado de células do sangue humano.

Os equilíbrios de oxigênio para o sangue do adulto e dos fetos de $T$. compressicauda são mostrados na Fig. 2. O valor de log $P_{50}$ para sangue de adulto e feto a $20^{\circ} \mathrm{C}$ e $30^{\circ} \mathrm{C}$ estão plotados contra $\alpha \mathrm{pH}$ do sangue. Cada ponto representa o resultado com uma amostra de sangue de um diferente indivíduo. A figura 2 também indica em quais pontos foram usados $5,6 \%$ de $\mathrm{CO}_{2}$ para baixar o $\mathrm{pH}$ do sangue. Nenhum tampão foi usado em qualquer dos experimentos com o sangue total. A variação do $\mathrm{pH}$ do sangue entre indivíduos foi, presumivelmente, causada pelas diferentes quantidades de lactato no sangue gerado pelo esforço animal, diferenças nos níveis de ATP ou variações na capacidade de tamponamento do sangue de diferentes indivíduos. A $30^{\circ} \mathrm{C}$ o $\mathrm{P}_{50}$ para o sangúe de espécies adultas aumenta de $10,5 \mathrm{~mm} \mathrm{Hg}$ a pH 7,8 para $36,3 \mathrm{~mm} \mathrm{Hg}$ a $\mathrm{pH}$ 7,01. A $20^{\circ} \mathrm{C}$ o $\mathrm{P}_{50}$ do sangue do adulto aumenta de $8,4 \mathrm{~mm} \mathrm{Hg}$ a $\mathrm{pH} 7,76$ para $14,8 \mathrm{~mm} \mathrm{Hg}$ a $\mathrm{pH} 7,30$. O $\mathrm{P}_{50}$ para o sangue do feto a $30^{\circ} \mathrm{C}$ aumenta de $7,9 \mathrm{~mm} \mathrm{Hg}$ a pH 7,69 para $8,6 \mathrm{~mm}$ $\mathrm{Hg}$ a pH 7,38 . A $20^{\circ} \mathrm{C} \circ \mathrm{P}_{50}$ do sangue fetal não mostra nenhuma troca entre $\mathrm{pH} 7,3$ e 7,8 . Um ótimo ajuste de regressão linear traçada através dos pontos da Fig. 2 pelo método da soma dos quadrados, indica que o fator Bohr $\left(\Delta \log \mathrm{P}_{50} / \Delta \mathrm{pH}\right.$ ) igual a $-0,58$ para o sangue dos adultos a $20^{\circ} \mathrm{C}$ e $30^{\circ} \mathrm{C} ;+0,02$ para o sangue dos fetos a $20^{\circ} \mathrm{C}$ e $-0,14$ para o sangue dos fetos a $30^{\circ} \mathrm{C}$.

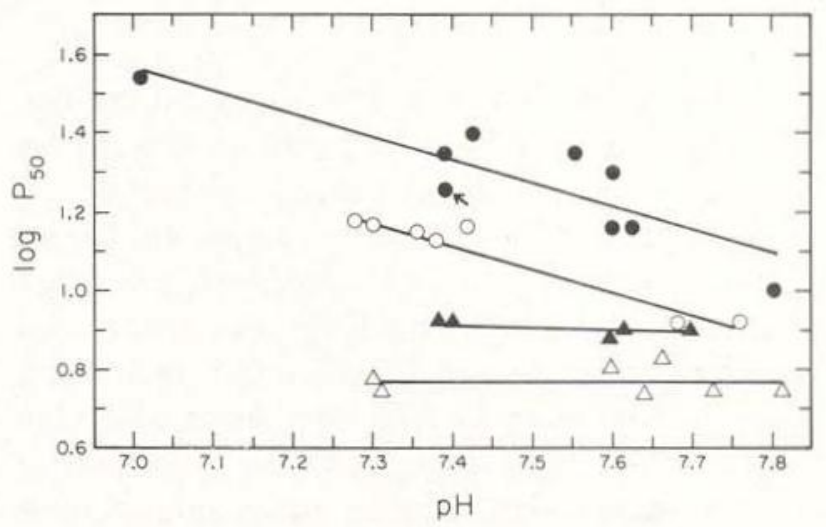

Fig. 2 - Efeito do $\mathrm{pH}$ e temperatura sobre a afinidade de oxigênio do sangue total em adultos e feítos de T. cmpressicauda. $O$ valor de $\log P_{50}$ para a totalidade de sangue foi obtido usando-se 0 analisador de dissociação de oxigênio Hem-O-Scan. Cada ponto representa um valor de $\log P_{50}$ de sangue obtido de um individuo. Todos os pontos abaixo de $\mathrm{pH} 7,5$, exceto o ponto marcado com uma seta, representa os experimentos nos quais foram usados $5,6 \%$ de dióxido de carbono. Todos os outros pontos foram obtidos na ausência de dióxido de carbono. $30^{\circ} \mathrm{C} ; \quad$, sangue de adulto a $20^{\circ} \mathrm{C} ; \boldsymbol{\Lambda}$. sangue fetal a 30-C; $\Delta$, sangue fetal a $20^{\circ} \mathrm{C}$. As condiçōes são descritas no texto.

Embora as medidas com o sangue total (Fig. 2) mostrassem que o sangue fetal das células vermelhas perderam o efeito Bohr encontrado no adulto, o comportamento das hemoglobinas fracionadas, isoladas dos fetos não foram distintas das do sangue dos adultos. Estes resultados (Fig. 3 e 4 ) mostram que os dados para as hemoglobinas dos adultos e dos fetos parecem ser diretamente sobrepostas dentro dos limites de erro. Nenhuma hemoglobina tem um efeito Bohr fisiologicamente significativo na ausência de fosfato orgânico e cada uma tem uma alta afinidade de oxigênio: 
o valor de $\mathrm{P}_{50}$ a pH 7,5 e $20^{\circ} \mathrm{C}$ é cerca de $2 \mathrm{~mm}$ $\mathrm{Hg}$ e $\Delta \log \mathrm{P}_{50} / \Delta \mathrm{pH}$ não é mais que $+0,02$ abaixo de $\mathrm{pH} 6,5$. A afinidade do oxigênio de ambas as hemoglobinas decresce na presença de $1 \mathrm{mM}$ de ATP e um substancial efeito Bohr aparece. A pH 6,5 e $20^{\circ} \mathrm{C}$ o valor de $\mathrm{P}_{50}$ é aumentado de $2 \mathrm{~mm} \mathrm{Hg}$ na ausência de ATP para cerca de $9 \mathrm{~mm} \mathrm{Hg}$ em sua presença. O efeito Bohr máximo ocorre entre $\mathrm{pH} 7,5-8,0$ onde $\Delta \log \mathrm{P}_{\mathrm{s}_{0}} / \Delta \mathrm{pH}$ aumenta para cerca de $-0,45$.

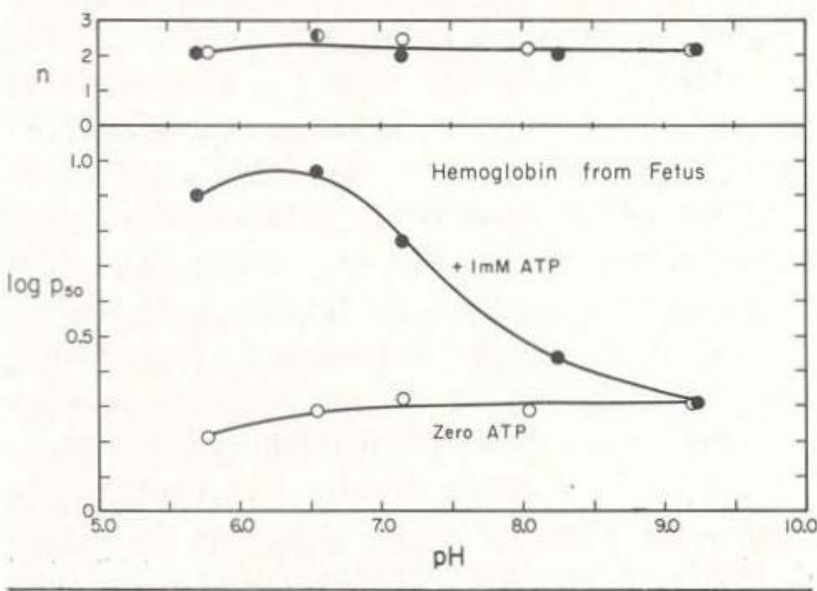

Fig. 3 - Distribuiçăo dos pontos de $\log \mathrm{P}_{50}$ e do coeficiente ' $n$ ' de Hill, versus $\mathrm{pH}$ de hemoglobinas de fetos T. compressicauda. As condições são como as descritas no texto. O, hemoglobina fracionada; (- hemoglobina fracionada mais $1 \mathrm{mM}$ de ATP.

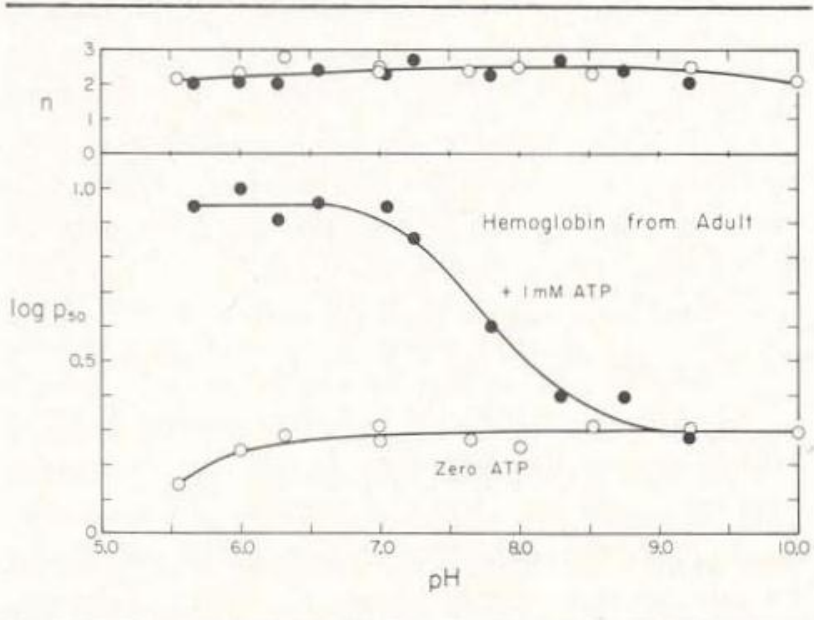

Fig. 4 - Distribuição de pontos de $\log P_{50}$ e ' $n$ ' versus $\mathrm{pH}$ de hemoglobina de adulto de $\mathrm{T}$. compressicauda. , hemoglobina fracionada; , hemoglobina fracionadada mais $1 \mathrm{mM}$ de ATP.

Medidas de velocidade de dissociação de oxigểnio das hemoglobinas dos adultos (Fig. 5) entre $\mathrm{pH} 5,5$ e 9,0 mostra que a velocidade é só ligeiramente dependente do $\mathrm{pH}$ na ausên- cia de fosfato mas que a dependência do $\mathrm{pH}$ aumenta enormemente na presença de $1 \mathrm{mM}$ de ATP. A troca é qualitativamente consistente com as trocas observadas na afinidade do oxigênio (Fig. 4). A velơcidade de combinação de $\mathrm{CO}$ (Fig. 6) tem sido medida entre $\mathrm{pH} 5,5$ e 7,5 na ausência de fosfato, mas somente abaixo de $\mathrm{pH} 7$ na presença de ATP.

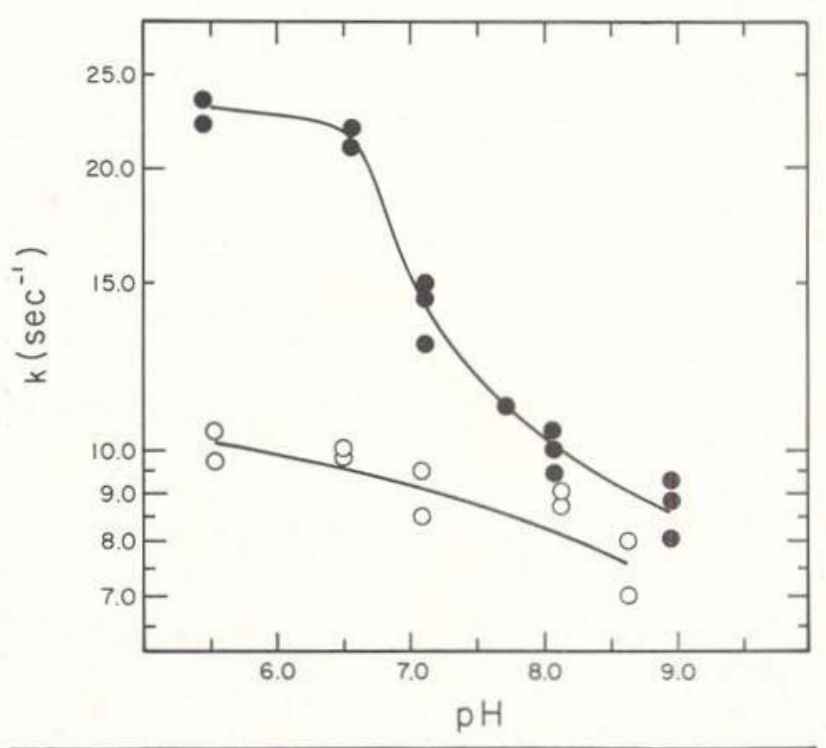

Fig. 5 - Velocidade de dissociação de oxigênlo de hemoglobina de adulto de T. compressicauda plotadas versus $\mathrm{pH}$. $\mathrm{O}$, hemoglobina fraclonada; globina fracionada mais $1 \mathrm{mM}$ de ATP. As condiçőes são como no texto.

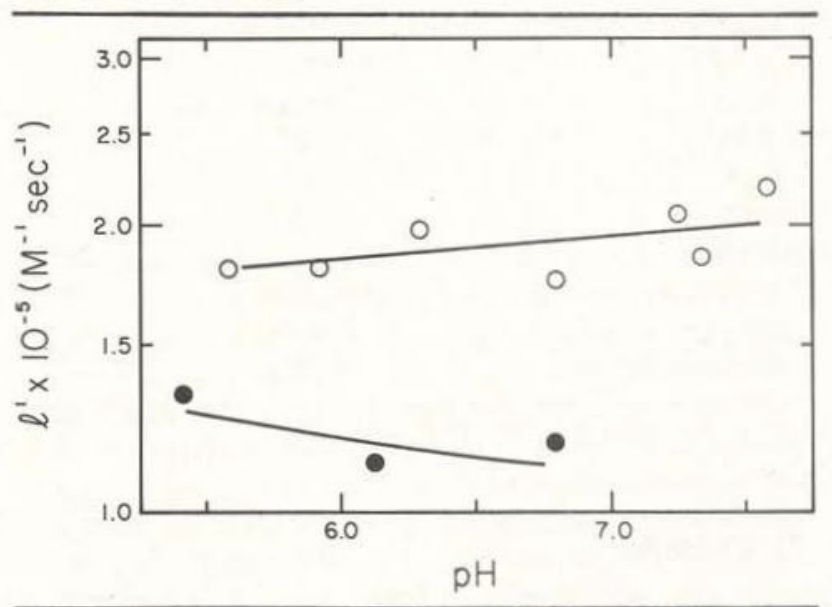

Fig. 6 - Velocidade de combinaçăo de monóxido de carbono com hemoglobina de adulto de T. compresslcauda plotada versus $0 \mathrm{pH}$. $\bigcirc$, hemoglobina fracionada; - hemoglobina fracionada mais $1 \mathrm{~m}$ MATP.

A análise enzimática do nucleosídeo trifosfato, resumida na Tabela 1, usou dois processos: (1) um ensaio enzimático não específico 
do total de necleosídeo trifosfato e (2) um ensaio pela produção de luz com o sistema luciferina-luciferase. Estes resultados mostram que os eritrócitos do adulto continham cerca de 1,9 moles de NTP por mole de hemoglobina, virtualmente tudo o que poderia ser contido como ATP, enquanto que as células vermelhas do feto continham somente $1 / 3$ das contidas no ATP. Uma cromatografia de camada fina no nucleosídeo trifosfato dos eritrócitos dos adultos indicaram que cerca de $90 \%$ do NTP está como ATP e cerca de 10\% como GTP. A dispersão de NTP estimada (Tab. 1) é grande e bastante para suportar esta pequena quantidade de GTP. .

TABELA I - Concentração de nucleosídeo trifosfato nos eritrócitos de Typhlonectes compressicauda

\begin{tabular}{ll}
$\begin{array}{ll}\text { Moles ATP/Mole } \mathrm{Hb}^{\bullet} \\
\text { (Análise com luciferase) }\end{array}$ & $\begin{array}{c}\text { Moles NTP/Mole } \mathrm{Hb} \\
\text { (Processo Sigma) }\end{array}$ \\
$\begin{array}{l}\text { Espécimes adultos } \\
1.80\end{array}$ & $\begin{array}{l}\text { Espécimes adultos } \\
1.44\end{array}$ \\
1.89 & 2.12 \\
1.90 & 2.23 \\
1.94 & 1.95 \\
\hline $1.88 \pm 0.05$ & \\
& $1.94 \pm 035$ \\
Espécimes fetais & \\
0.69 & Espécimes fetais \\
0.71 & 0.68 \\
0.61 & 0.35 \\
0.38 & 0.60 \\
0.95 & 0.38 \\
0.50 & 1.02 \\
0.44 & 0.72 \\
\hline $0.61 \pm 0.19$ & 0.23 \\
\hline
\end{tabular}

(•) Baseada na hemoglobina tetrâmera.

\section{DISCUSSÃo}

Towes \& Macintyre (1977) descobriram que os fetos de caecílios aquáticos, $T$. compressicauda, possuem sangue com maior afinidade pelo oxigênio que os do adulto. Nossos resultados mostram que esta "troca materno-fetal" não resulta de diferenças intrínsecas nas hemoglobinas "mas sim na concentração de ATP 3 vezes maior nas células dos adultos quando comparadas com as do sangue dos fetos. As hemoglobinas dos fetos e dos adultos parecem ter idênticas propriedades de ligação com o oxigênio. Elas são eletroforeticamente indistinguíveis e podem ser estruturalmente idênticas.

A diferença de 3 vezes na concentração de ATP parece também ser responsável pelo substancial efeito Bohr das células dos adultos, efeito que é perdido nas células dos fetos. A mais provável explicação para esta diferença funcional, entre os sangues, parece ser a seguinte: se o ATP age aqui como os fosfatos orgânicos fazem com outras hemoglobinas (ver revisão por Kilmartin \& Rossi-Bernardi, 1973), ela faz então ligando-se preferencialmente à deóxi-hemoglobina. Nossos resultados mostram que, na ausência de fosfato, a dependência do $\mathrm{pH}$ da ligação do oxigênio (efeito Bohr) é próxima de zero, isto é, o número de prótons ligados a oxi e deóxi hemoglobinas é o mesmo. O efeito Bohr então resulta das ligações do ATP preferencialmente se uma série de grupos protonados na deoxi-hemoglobinas. As ligações, com efeito, aumentam o valor de pK destes grupos, os quais poderiam ter o mesmo valor de pK, nas formas oxi e deóxi, na ausência de ligações específicas. As quatidades menores de ATP, nas células vermelhas fetais, o efeito Bohr poderia resultar grandemente diminuído. O efeito Bohr residual que poderia resultar pela presença de 0,6 moles de ATP por mole de hemoglobina (tetrâmero) pode ser coberto pela extensão dos pontos para o total de sangue desde que o valor de $P_{50}$ para o sangue fetal seja cerca de $6 \mathrm{~mm} \mathrm{Hg}$ a $20^{\circ} \mathrm{C}$ e são incertos por volta de $0,5-1,0 \mathrm{~mm} \mathrm{Hg}$.

A possibilidade que a hemoglobina fetal $e$ adulta possa ser idêntica é curiosa mas não sem precedente. Hemoglobinas fetais de cavalo, cachorro e porco parecem ser idênticas às dos adultos (Stockell et al., 1961; LeCrone, 1970; Kleihauer \& Tautz, 1972; Tautz \& Kleihauer, 1972). Os fetos de $T$. compressicauda estavam em avançado estágio de desenvolvimento. Uma hemoglobina de embrião, distinta das hemoglobinas fetais podem estar presentes em estágios mais novos de desenvolvimento. Uma hemoglobina de embrião ou de larva tem sido encontrada em representantes de outras duas ordens de anfíbios viventes. Por exemplo, girinos, de sapo-boi, Rana catesbeia- 
na, tem 4 hemoglobinas principais. Os compoponentes I e II presentes em girinos muito jovens tem significantemente mais alta afinidade pelo oxigênio que os componentes III e IV, os quais predominam em girinos mais velhos (Watt \& Riggs, 1975). A hemoglobina dos girinos com alta afinidade são substituídas pelos de mais baixa afinidade, após a metamorfose (McCutcheon, 1936; Riggs, 1951). Duas hemoglobinas são encontradas nos girinos de salamandra, Ambystoma mexicanum, as quais são substituídas por outros diferentes componentes nos adultos. Nenhuma troca na hemoglobina ocorre quando os adultos neutônicos sofrem o fenômeno da metamorfose (Maclean \& Jurd, 1971).

Comparando nos nossos resultados obtidos com o sangue dos caecilios aquáticos, Typholonectes compressicauda, com os resultados obtidos por Wood et. al. (1975) com caecilios terrestres (Africa), Boulengerula taitanus, comprovamos que o primeiro tem uma muito maior afinidade pelo oxigênio do que os de B. taitanus, Wood et al., (1975) fornecem dados sobre a afinidade pelo oxigênio da hemoglobina fracionada de $B$. taitanus a $10^{\circ} \mathrm{C}$ e $25^{\circ} \mathrm{C}$. $\mathrm{O}$ valor de $\log \mathrm{P}_{50}$ é cerca de 0,55 a $25^{\circ} \mathrm{C}$. A entalpia aparente de $19,4 \mathrm{~K} \mathrm{cal} / \mathrm{mol}$ permite cálculos do valor de log $P_{50}$ esperado a $20^{\circ} \mathrm{C}$, o qual corresponde a 0,31 para a hemoglobina de $B$. taitanus, que é Idêntica à obtida para a hemoglobina de $T$. compressicauda. Wood et al. (1975) descrevem que o efeito Bohr da hemoglobina fracionada de $B$. taitanus é muito pequena e que o efeito do ATP é também pequeno. Desde que a afinidade do oxigênio do sangue para as duas espécies difira grandemente, o que não ocorre para as hemoglobinas, algum outro fator não envolvendo a própria hemoglobina precisa ser responsabilizada pelas diferenças no sangue total.

A mais alta afinidade do oxigênio do sangue nas formas aquáticas não é imprevista. Um levantamento do sangue de anfíbios (Lenfant \& Johansen, 1967, e Johansen \& Lenfant, 1972) mostra uma clara tendência para com as mais baixas afinidades de $\mathrm{O}_{2}$ nos sangues dos anfíbios, os quais contam com mais $\mathrm{O}_{2} \mathrm{em}$ seus pulmões do que as formas aquáticas que podem utilizar troca de $\mathrm{O}_{2}$ pela cavidade bucal, brânquias ou pele. Embora $T$. compressicauda provavelmente troque oxigênio mais freqüentemente pelos pulmões, $\mathrm{CO}_{2}$ é parcialmente eliminado através da pele (Sawaya, 1947). A alta afinidade de oxigênio do sangue dos $T$. compressicauda pode também estar associada com o ambiente aquoso relativamente hipóxico em que são encontrados.

\section{AGRADECIMENTOS}

Este trabalho foi financiado pelo subsídio PCM-06451 de National Science Foundation para estudos a bordo do R/V "Alpha Helix". Estamos agradecidos aos brasileiros por sua ajuda por terem permitido que o R/V "Alpha Helix" entrasse em águas amazônicas. Gostaríamos de agradecer ao Capitão Clarke e tripulação por sua cooperação. Subvenção adicional foi cedida por Norweigian Research Council for Science and Humanities (H.J. e U.E.H.F.), subsídio NSF-DEB-76-19877 (D.A.P.), NIH-HL15460 (a J. Bonaventura, pela ajuda a M.F.) NSF-PCM-76-06719 (A. R.) e NIH-BM-21314 (A.R.), da Universidade of Texas Research Institute (A.R.) e de National Geographic Society (D.A.P.). Auxilio $n .^{\circ}$ 303-3765 a M. Farmer da Duke University Research Award.

\section{SUMMARY}

The equilibria and kinetics of oxygen binding by blood and hemoglobin from adult and fetal caecilians, Typhlonectes compressicauda, have been measured. The oxygen affinity of fetal blood is higher than that of adult blood. Electrophoresis of adult and fetal hemoglobins suggests that they may be identical; a major and minor component occurs in each. Adult and fetal hemoglobins have identical oxygen equilibria. Stripped hemoglobins have a high oxygen affinity and no Bohr effect between pH 6.5 and 10.0. An "acid", reversed Bohr effect is present below $\mathrm{pH}$ 6.5. The addition of $1 \mathrm{mM}$ ATP reduces the oxygen affinity markedly and produces a moderate, normal Bohr effect. The major nucleoside triphosphate in fetal and adult erythrocytes is adenosine triphosphate; about $10 \%$ of the nucleoside triphosphates Is guanosine triphosphate. Adult erythrocytes contain 3 times as much ATP as do the fetal erythrocytes. The fetal to maternal shift in the oxygen equilibrium is mediated entirely by the difference in ATP content of the maternal and fetal red blood cells. 


\section{BIBLIOGRAFIA}

Cashel, M.; lazzarini, R. A. \& Kalbachu, B.

1968 - An improved method for thin-layer chromatography of nucleotide mixtures containing 32p-labeled orthophosphate. J. Chromatog. 40, 103-109.

Estes, R. \& WAKE, M.

1972 - The first fossil record of caecilian amphlblans Nature 239, 228-231.

Fyhn, U. E. H.; FyhN, H. J.; Davis, B. J.;

Powers, D. A.; Fink, W. L. \& GArLICK, R. L.

1978 - Heterogeneidade de hemoglobinas nos peixes da Amazônica. Acta Amazonica $8(4)$ : Suplemento. (Este volume).

Gibson, Q. H. \& Milnes, L.

1964 - Apparatus for rapid and sensitive spectrophotometry. Biochem. J. 91, 161-171.

Greaney, G. S. \& Powers, D. A.

1077 - Allosteric modifiers of fish hemoglobins : In vitro and in vivo studies of the effect of ambient oxygen and $\mathrm{pH}$ on erythrocyte ATP concentration. J. Exp. Zool. (In the press).

JOHANSEN, K. \& LENFANT, C.

1972 - A compaartive aproach to the adaptabillity of $\mathrm{O}_{2}-\mathrm{Hb}$ affinity. In: Oxygen affinitiy of hemoglobin and red cell acid base status. (ed., P. Astrup and M. Rorth), Munksgaard, Copenhagen. pp. 750-780.

Kilmartin, J. V. \& Rossi-Bernard, L.

1973 - Interaction of Hemoglobin with Hydrogen Ions, Carbon Dioxide, and Organic Phosphates. Physiol. Rev. 63, 836-890.

Kleihauer, E. \& Tautz, C.

1972 - Gibt es ein fetales Hämoglobin belm Schwein? I. Analysen des Hämoglobins. Resp. Exp. Med., 158, 219.

LENFANT, C. \& JOHANSEN, K.

1067 - Respiratory adaptations in selected amphlbians. Resp. Physiol. 2, 247-260.

Le Crone, C. N.

1970 - Absence of special fetal hemoglobin In beagle dogs. Blood 35, 451-452.

Maclean, N. \& JuRd, R. D.

1971 - Electrophoretic analysis of the haemoglobln of Ambystoma mexicana Comp. Biochem. Physiol. 40B, 751-755.

MCCUTCHEON, F. G.

1936 - Hemoglobin function during the life hlstory of the bullfrog. J. Cell. Comp. Physiol. 8, 63-81.

MURPhy, J. B; QUinN, H. \& CaMpbell, J. A.

1977 - Observations on the breeding habits of the aquatic caecilian, Typhlonectes compressicaudus. Copeia, 66-69.
Noble, R. W.; Parkhurst, L. J. \& Gibson, Q. H.

1970 - The effect of $\mathrm{pH}$ on the reaction of oxygen and carbon monoxide with the hemoglobin of the carp, Cyprinus carplo. J. Biol. Chem. 245, 6628-6633.

PARKer, H. W.

1956 - Viviparous caecilians and amphibian phylogeny. Nature 178, 250-252.

Peters, W.

1875 - Ober die Entwickelung der Caecilien und besorders der Caecilia compressicauda. Monatsber. Akad. Wissen. Berlin, 45-49.

Powers, D. A.; Fyhn, H. J.; Fyhn, U. E. H.; Martin, J. P.;

GARLICK, R. L. \& WOOD, S. C.

1978 - Estudo comparativo de equilíbrio de oxigênio no sangue de 40 gêneros de peixes da Amazônia. Acta Amazonica $8(4)$ : Suplemento. (Este volume).

RIGGS, A.

1951 - The metamorphosis of hemoglobin In the bullfrog. J. Gen. Physlol. 35, 23-40.

Rigos, A. F. \& Wolbach, R. A.

1956 - Sulfhydryl groups and the structure of hemoglobin. J. Gen. Physiol. 39, 585-605.

SAWAYA, P

1947 - Metabolismo Respiratório de Anfíbio Gymnophinona, Typholonectes compressicauda (Dum. et Bibr.), Bol. Fac. Fil. Ciên. Ltr. Univ. S. Paulo, Zool. 12, 51-56.

Stockell, A.; Perutz, M. F.; Muirhead, H.

\& Glauser, S. C.

2961 - A comparison of adult and foetal horse haemoglobin. J. Mol. Biol. 3, 112-116.

TAUtz, C. \& KLeihuUer, E.

1972 - Gibt es eln fetales Hämogllobin beim Schwein ? II. Analysen des Globins. Resp. Exp. Med. 159, 44-49.

TAYLOR, E. H.

1968 - The Caecilians of the World, Univ. of Kansas Press, Lawrence. 848 pp.

Toews, D. \& Macintyre, D.

1977 - Blood respiratory properties of a viviparous amphibian. Nature 266, 464-465.

WATT, K. W. K. \& RIGGS, A.

1975 - Hemoglobins of the tadpole of the bullfrog, Rana catesbeiana. Structure and function of isolated subunits. J. Biol. Chem. 250, 5934-5944.

Weber, R. E.; Lykkeboe, G. \& Johansen, K.

1976 - Physiological properties of eel hemoglobln : hypoxic acclimation, phosphate effects and multiplicity. J. Exp. Biol. 64, 75-88.

Wood, S. C.; Weber, R. E.; Malory, G. M. D.

\& JoHANSEN, $\mathbf{K}$.

1975 - Oxygen uptake and blood resplratory properties of the caecilian Boulengerula taitanus, Resp. Physiol. 24, 355-363. 